\title{
Investigating coping strategies and social support among Canadian melanoma patients: A survey approach
}

\author{
by Melanie Kalbfleisch, Annette Cyr, Nancy Gregorio, Joyce Nyhof-Young
}

\begin{abstract}
Complex support needs are involved in coping with a diagnosis of melanoma. The purpose of this study was to determine the perceived social support levels and utilization of adaptive and maladaptive coping strategies by Canadian melanoma patients. The impact of social support level on coping strategy utilization was also examined. Social support and coping strategies were assessed using the Medical Outcomes Study Social Support Survey (MOS-SSS) and the 28-item Brief COPE, respectively. Perceived levels of emotional/informational support were significantly lower than affectionate support and positive social interaction. Acceptance, active coping, and use of emotional support were the most frequently utilized coping strategies. Patients with higher perceived levels of social support had significantly higher adaptive coping scores than patients with lower levels of social support. Health care professionals have an important role in promoting awareness of and access to emotional and informational support resources in order to improve perceived social support levels.
\end{abstract}

Key points:

- Individuals with melanoma utilize a wide variety of coping strategies.

- Emotional and informational support enhances effective coping.

- Perceived social support can be strengthened in individuals with melanoma by providing resources regarding emotional and information support.

- Initial assessment of social support is important to identify who will benefit from targeted education interventions.

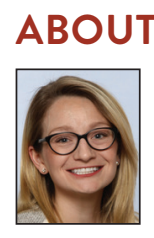

THE AUTHORS

Melanie Kalbfleisch, BMSc, University of Western Ontario (2011), MD Candidate (2015), Faculty of Medicine, University of Toronto, Toronto, ON M5S 1A8

Phone: 289-981-9394

Email: melanie.kalbfleisch@mail.utoronto.ca

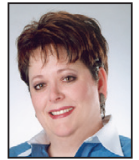

Corresponding author: Annette Cyr, Chair \& Founder, Melanoma Network of Canada, 99 Bronte Road, Box 324, Oakville, ON L6L $3 B 7$

Phone: 289-242-2010

Email: acyr@melanomanetwork.ca

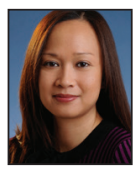

Nancy Gregorio, BScN, MN, OCN, CON(C), Specialized Oncology Nurse, Princess Margaret Cancer Centre Ambulatory Clinics, 610 University Avenue, Toronto, ON M5T 2M9

Phone: 416-946-4501 X 5543

Email: nancy.gregorio@uhn.ca

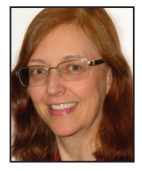

Joyce Nyhof-Young, BSc, MSc, PhD, Cirriculum Evaluation, Coordinator, Undergraduate Medical Education, University of Toronto; Associate Professor, Family \& Community Medicine, Helliwell Medical Education Centre, Toronto General Hospital, 200 Elizabeth Street, Toronto, ON, Canada, M5G 2C4 Email: joyce.nyhof-young@uhn.ca

DOI: $10.5737 / 236880762516065$

\section{INTRODUCTION}

$\mathrm{M}$ elanoma is one of the fastest growing cancers worldwide (Garbe \& Leiter, 2009). Many aspects of an individual's health are influenced by a melanoma diagnosis, including self-identity, body image, well-being, relationships, career opportunities, and finances (Zabora, Brintzenhofeszoc, Curbow, Hooker, \& Piantadosi, 200I; Kasparian, McLoone, \& Butow, 2009). Approximately 30\% of melanoma patients report psychological distress levels indicative of the need for psychological therapy (Kasparian et al., 2009; Zabora et al., 200I; Trask et al., 200I). Social support is the support accessible to an individual through social ties to other individuals, groups and the larger community; it is thought to play a critical role in the psychological adjustment of melanoma patients (Lichtenthal et al., 2003). Devine, Parker, Fouladi, and Cohen (2003) showed that better psychological adjustment one month after treatment was predicted by greater social support and fewer intrusive and avoidant thoughts amongst 53 patients with metastatic melanoma and renal cell cancer. The authors suggest that cognitive processing of a traumatic event may be mediated by available social support, allowing patients to assimilate the cancer experience into their views of the self and the world (Devine et al., 2003; Kasparian et al., 2009).

Utilization of adaptive coping strategies, defined as the tendency to react to or deal with problems in a constructive, direct and positive manner (Trapp et al., 20I2), is also important for cancer patients, as they experience a range of psychological reactions to and challenges after their diagnosis. Higher appraisal of the subjective ability to cope with melanoma is associated with increased well-being and reduced psychological distress (Hamama-Raz, Solomon, Schachter, \& Azizi, 2007). Fawzy (I995) showed that a nursing intervention including coping skills teaching decreased psychological distress levels. Maladaptive strategies are the tendency to react to or deal with problems in an avoidant or unconstructive manner (Trapp et al., 20I2). Social support and coping strategies are highly interdependent. For example, how a person copes with a stressful life situation may influence their social network's readiness or ability to provide support. The individual who uses behavioural disengagement as a coping strategy may withdraw from their friends and family, who may, in return, feel discouraged to offer their help. Conversely, those who actively seek emotional support from their social network encourage its responsiveness (Schreurs \& DeRidder, 1997).

Health care professionals play an important role in melanoma patient support by assessing psychological and emotional status, providing psychological support, promoting the use of adaptive coping strategies, and educating patients about 
available resources (Boyle, 2003). Many education and support services are available to melanoma patients, including the Melanoma Network of Canada (MNC), a national patient-led organization dedicated to the prevention and elimination of melanoma (www.melanomanetwork.ca). Established in 2009 by patients and caregivers, the MNC collaborates with medical professionals, health care agencies and other stakeholders to educate, advocate and fund early diagnosis and effective treatment for melanoma; education, prevention and awareness programs; relevant and innovative research; support for patients, and an improved quality of life for those living with melanoma. Given that the MNC is one of the largest Canadian organizations supporting melanoma patients, its members were recruited to participate.

Coping strategies and social support resources are not well examined amongst Canadian melanoma patients. Therefore, this study investigated their: (I) perceived levels of social support; (2) frequencies of different coping strategies; and (3) associations between social support and utilization of adaptive or maladaptive coping strategies. The available literature suggests there are many different coping behaviour patterns applied by melanoma patients, indicating the provision of different types of social support. Increased knowledge about preferred coping strategies of melanoma patients may allow for the development of more targeted social support interventions by support agencies.

\section{METHODS}

This study was a cross-sectional quantitative survey investigating social support and coping strategies amongst MNC members. The survey included three sections: (I) demographics (gender, age, marital status, employment status, ethnic background, and education level); (2) perceived levels of social support (emotional/informational, tangible, affectionate, and positive social interaction); and (3) coping strategy utilization.

Coping strategies were assessed using the 28-item Brief COPE questionnaire. The full 7x-item version of the COPE Inventory has been used in patients with malignant melanoma (Vurnek, Buljan, \& Situm, 2007). The validity and reliability of the Brief COPE scale has also been established with breast cancer patients (Yusoff, Low, \& Yip, 20Iо). The questionnaire uses a four-point scale ranging from "I haven't been doing this at all (score I) to "I have been doing this a lot" (score 4). In total, I4 dimensions are investigated with two items each, including adaptive coping strategies (active coping, instrumental coping, planning, acceptance, emotional support, humour, positive reframing and religion) and maladaptive coping strategies (behavioural disengagement, denial, self-distraction, self-blame, substance use and venting) (Murtaza Kasi et al., 20I2; Zhou et al., 20IO). Note that the Brief COPE scale is not specific to the experience of melanoma patients. For example, 'active coping' is assessed by two generic statements: 'I've been concentrating my efforts on doing something about the situation I'm in' and 'I've been taking action to try to make the situation better'. The Brief COPE tool is available online: http://www.psy.miami.edu/faculty/ccarver/sclBrCOPE.html.
Social support was measured using the Medical Outcomes Study-Social Support Survey (MOS-SSS), a I9-item self-report tool measuring four aspects of functional support: (I) emotional/ informational support (expression of positive affect, empathetic understanding, and the encouragement of expression of feelings, offering of advice, information, guidance or feedback); (2) tangible support (provision of material aid or behavioural assistance); (3) affectionate support (expressions of love and affection); and (4) positive social interaction (availability of others to have fun with) (Sherbourne \& Stewart, I99I). The MOS-SSS has been used extensively to assess the perceived social support levels of cancer patients, including those with melanoma, supporting its use as a valid instrument for this study (Costa Requena, Salamero, \& Gil, 2007; Gil, Costa, Hilker, \& Benito, 20I2; LehtoJanstedt, Ojanen, \& Kellokumpu-Lehtinen, 2004).

The questionnaire was sent by email in early February 2013 using on online survey tool known as Fluid Surveys (www.fluidsurveys.com). The only modification to the surveys was a preceding statement to explain the context in which to base responses: 'Your responses to these statements should be based upon your experience with melanoma'. Those without email access were excluded, a potentially limiting factor for response rates (see discussion). A consent letter outlined the study's aims, survey content, and potential participation risks. All patients were current or past members of the MNC. Patients were informed that they could withdraw from the survey at any time before submitting their responses. Two follow-up reminders were sent one-and-a-half weeks apart. Data collection ended mid March, 20I3.

Mean social support scores within and across the four domains (emotional/informational, tangible, and affectionate support and positive social interaction) were calculated, as well as coping strategy scores for each participant (Rand Health, 2OII). First, patients above the median social support score were classified as "high social support" and those below were classified as "low social support". This methodology was derived from a study by Daly, Douglas, Lipson, and Foley (2009), who used the MOS-SSS to stratify caregivers of newly diagnosed adult cancer patients into high and low levels of social support and examined several measures of well-being between the two groups. Second, one-way ANOVA with Tukey's multiple comparisons tests were used to compare scores between each of the four social support domains and determine if melanoma patients report significantly more support in one domain over another. Finally, the Mann-Whitney U test was used to examine the relationships between social support and coping strategy utilization, specifically if high social support was associated with higher adaptive coping scores. All statistical comparisons were two-sided, using $\mathrm{p}<0.05$ as the significance level. GraphPad Prism Software (La Jolla California USA, www.graphpad.com) was used for all statistical analyses.

\section{RESULTS}

\section{Sample characteristics}

Overall, 32I patients were contacted by e-mail to participate in the survey. Of this population, 46 (I4.3\%) provided complete responses. The average patient age was 6o.I years 
\pm 9.I (SD); $43 \%$ were male and $57 \%$ female. The majority of patients were legally married $(74 \%)$ and educated beyond the high school level (86\%). Thirty-six per cent were retired, I2\% were unable to work, I $8 \%$ self-employed, and $24 \%$ employed for wages.

\section{Social support levels of melanoma patients}

Social support levels are reported as mean \pm SD. Levels of emotional and informational support were the lowest among the participants $(3.50 \pm 1.06)$, followed by tangible support $(3.88 \pm$ I.I5). The highest level of support reported by patients was affectionate $(4.25 \pm \mathrm{I} .06)$; the second was highest positive social interaction (4.OI \pm I.04). One-way ANOVA with multiple comparisons analysis found that reported levels of emotional and informational support were significantly lower than both affectionate support $(\mathrm{p}<0.000 \mathrm{I})$ and positive social interaction $(\mathrm{p}=0.002)$.

Coping strategy utilization by melanoma patients

In the Brief COPE scale, higher scores indicate more use of particular coping strategies. Of the I4 coping styles, the most frequently used by respondents were acceptance $(3.07 \pm 0.83)$, active coping $(3.07 \pm 0.86)$, and emotional support $(2.64 \pm$ $0.90)$. The least frequently used strategies were behavioural disengagement (I.I4 \pm 0.33), substance use (I.I9 \pm 0.53),

Table 1: Ranked coping strategy scores (mean and SD) reported by melanoma patients based on the Brief COPE questionnaire

\begin{tabular}{|l|l|l|}
\hline Brief COPE Coping Strategy & Mean & SD \\
\hline \multicolumn{2}{|l|}{ Maladaptive Coping Strategies } \\
\hline Self-Distraction & 2.39 & 1.00 \\
\hline Venting & 1.75 & 0.74 \\
\hline Self-Blame & 1.49 & 0.74 \\
\hline Denial & 1.26 & 0.43 \\
\hline Substance Use & 1.19 & 0.53 \\
\hline Behavioural Disengagement & 1.14 & 0.33 \\
\hline Adaptive Coping Strategies & & \\
\hline Acceptance & 3.07 & 0.83 \\
\hline Active Coping & 3.07 & 0.86 \\
\hline Use of Emotional Support & 2.64 & 0.90 \\
\hline Planning & 2.52 & 1.00 \\
\hline Use of Instrumental Support & 2.36 & 0.84 \\
\hline Positive Reframing & 2.20 & 0.96 \\
\hline Religion & 2.13 & 1.06 \\
\hline Humour & 1.45 & 0.72 \\
\hline
\end{tabular}

and denial (ז.26 \pm 0.43). Behavioural disengagement was described as giving up trying to deal with problem or giving up the attempt to cope. The overall score for adaptive coping strategies was $2.77 \pm 0.64$, which was significantly higher ( $p$ $<0.000 \mathrm{I}$ ) than that for maladaptive coping strategies (I.54 \pm 0.36) (Table I).

Relationship between perceived level of social support and coping strategy utilization

Patients with high social support had a significantly higher median adaptive coping score (2.69) compared to patients with low levels of social support (2.3I) $(\mathrm{p}=0.03)$. Furthermore, patients with high levels of support had a lower median maladaptive coping score than those with low levels of social support (I.50 versus I.58), although this result was not statistically significant (Fig. I). The utilization of coping strategies amongst patients with low versus high levels of perceived social support was analyzed individually. Patients with low levels of social support had a significantly lower score for the use of emotional support, an adaptive coping strategy ( $p$ $<$ o.00I). In comparison to patients with high social support, patients with low social support also had lower scores in adaptive coping strategies, including active coping $(\mathrm{p}=0.09 \mathrm{I})$, positive reframing $(\mathrm{p}=0.3 \mathrm{I})$, planning $(\mathrm{p}=0 . \mathrm{I} 6)$, acceptance $(\mathrm{p}=$ $0.097)$, and humour $(\mathrm{p}=0.085)$. However, these results were not statistically significant.

There was also a notable difference between patients with low and high social support in the use of maladaptive coping strategies. Patients with high social support had significantly lower scores in behavioural disengagement than patients with low social support $(\mathrm{p}=0.03)$. They also had lower scores in denial ( $\mathrm{p}=0.67)$, substance use $(\mathrm{p}=0.097)$, and self-blame ( $\mathrm{p}$ $=0.4 \mathrm{I}$ ), although these results were not statistically significant. Of note, patients with high social support had higher scores for the use of venting $(p=0.55)$ and self-distraction $(p=0.52)$.
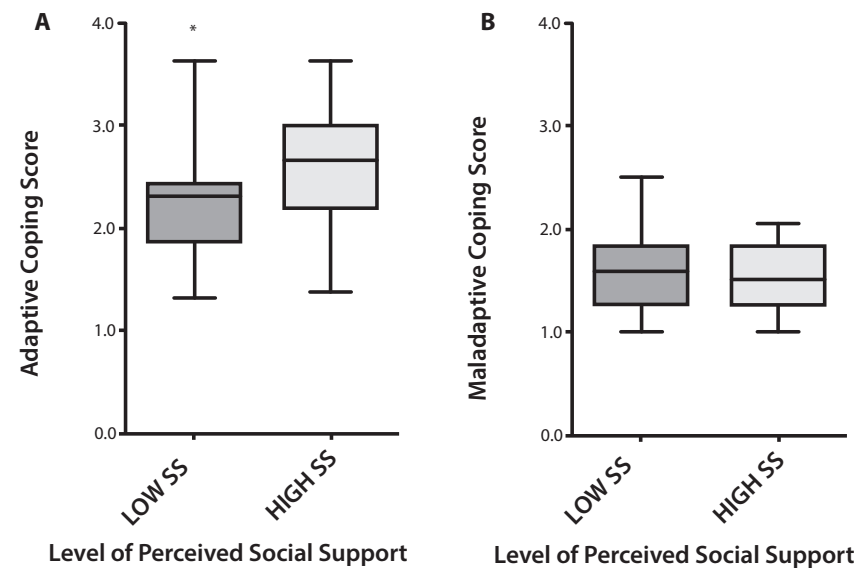

Figure I: Boxplots for adaptive coping strategies (A) and maladaptive coping strategies (B) in patients with low vs. high levels of perceived social support. The horizontal line indicates the median value; the bottom and top of the box are the 25th and $75^{\text {th }}$ percentiles of the distribution. The bars represent the upper and low limit of the distribution. Mann-Whitney U test, $* \mathrm{p}<0.05$ 


\section{DISCUSSION}

This study aimed to determine if an association existed between social support levels and coping strategies most often applied by Canadian melanoma patients. Coping and social support are often integrated as a single concept within the chronic disease literature, and few studies investigate them independently. Sollner and colleagues (I999) showed that melanoma patients reported highest perceived levels of instrumental support, followed by emotional support and affiliational support. Furthermore, they found that less depressive coping and greater adaptive coping were associated with greater emotional support. Similarly, in the present study, low social support levels were associated with significantly lower adaptive coping scores. However, the cause and effect relationship is difficult to ascertain. Social support may influence patient use of specific coping strategies based on the reaction of the patient's social network to his or her attitude (Schreurs \& DeRidder, 1997). Lower levels of available social support may predispose individuals to use maladaptive coping strategies, leading to increased isolation. The cyclical interaction between coping strategy utilization and perceived levels of social support may be positively influenced by patient advocacy organizations such as the MNC.

The MOS-SSS was used to assess four social support sources: emotional/informational, tangible and affectionate support, and positive social interaction. Melanoma patients scored the lowest in emotional/informational support (i.e., having someone to confide in and seek out for information, advice, understanding, and to share private worries and fears with). Most indicated having this support available only some of the time. Other cancer patients with more of such social support have reported lower levels of depression and a better perception of overall quality of life (Paredes, Canavarro \& Simões, 20I2). Interestingly, melanoma patients reported frequent use of emotional support as a coping strategy, defined by seeking comfort and understanding from others (Brief COPE score: 2.64). Emotional support is clearly very important to patients with a melanoma diagnosis and according to the MOS-SSS, they are not getting enough of it (MOSSSS score: $3 \cdot 5 \mathrm{I})$.

Health care professionals have the opportunity to inform melanoma patients about resources that provide emotional support beyond what they receive from friends and family members. For example, the Melanoma Network of Canada (MNC) offers nationally available resources such as the telephone support group (http://www.melanomanetwork.ca/ peer-support-teleconferences/), which allows melanoma patients and their caregivers to phone in and participate in a professionally facilitated discussion. This model of telephone-based social support has been shown to be an effective intervention for melanoma patients (Rudy, Rosenfeld, Galassi, Parker, \& Schanberg, 200I). The MNC website also hosts an online discussion forum, with discussion threads covering melanoma staging, self-skin examinations, treatments and their side effects and coping strategies (http://www.melanomanetwork.ca/forum/). See Table 2 for other online support resources.
Emotional and informational support was the only MOSSSS subscale that melanoma patients scored lower than patients with other forms of chronic disease (62.7\% melanoma patients versus $69.6 \%$ other chronic diseases) (Sherbourne $\&$ Stewart, I99I). For all other subscales, including tangible and affectionate support and positive social interaction, melanoma patients scored higher. These latter three social support domains may be fulfilled by the patient's loved ones, whereas emotional and informational support involves others who can relate to and understand the patient's experience. For example, tangible support is described as someone to help you if you were confined to bed, to take you to the doctor, to prepare your meals, etc., whereas emotional and informational support is described as seeking advice and speaking to someone who understands your problems. A recent program evaluation completed by the MNC (unpublished results) showed that the telephone support group and online discussion forum were the least frequently accessed support resources. Interestingly, these resources provide the most emotional and informational support for patients by allowing them to interact directly with others coping with melanoma. Increased awareness and uptake of these resources has the potential to improve perceived levels of emotional and informational support amongst melanoma patients.

Brief COPE questionnaire responses indicated that participants applied adaptive coping strategies significantly more often than maladaptive strategies, suggesting that, overall, they are coping relatively well with their diagnosis. Self-distraction was the most frequently applied maladaptive coping strategy, which involves turning to other activities to take one's mind off things. Arguably self-distraction may be initially an adaptive

\begin{tabular}{|l|l|}
\hline $\begin{array}{l}\text { Table 2: Online emotional and informational support resources } \\
\text { for Canadian melanoma patients }\end{array}$ \\
\hline Organization & Website \\
\hline $\begin{array}{l}\text { Canadian Cancer } \\
\text { Action Network }\end{array}$ & www.ccanceraction.ca \\
\hline $\begin{array}{l}\text { Canadian Cancer } \\
\text { Society }\end{array}$ & www.cancer.ca \\
\hline $\begin{array}{l}\text { Canadian Skin Cancer } \\
\text { Foundation }\end{array}$ & www.canadianskincancerfoundation.com \\
\hline $\begin{array}{l}\text { Canadian Skin Patient } \\
\text { Alliance }\end{array}$ & www.skinpatientalliance.ca \\
\hline $\begin{array}{l}\text { Melanoma Network of } \\
\text { Canada }\end{array}$ & www.melanomanetwork.ca \\
\hline $\begin{array}{l}\text { Save Your Skin } \\
\text { Foundation }\end{array}$ & www.saveyourskin.ca \\
\hline $\begin{array}{l}\text { Still Standing-A } \\
\text { group for malignant } \\
\text { melanoma survivors } \\
\text { and/or their support } \\
\text { circle }\end{array}$ & www.cancerconnection.ca \\
\hline
\end{tabular}


strategy, since continuously focusing on the disease could be detrimental for psychological health. However, some authors argue that self-distraction has a negative long-term effect because the patient is not directly addressing the problem or their emotional reaction to it (Vurnek et al., 2007). Conversely, acceptance was the most frequently applied adaptive coping strategy, i.e., learning to live with the situation and accepting it as a reality. This strategy is in direct contrast to self-distraction, because, by accepting the situation, the patient assumes a more active role in his or her health care, which may include seeking emotional and informational support.

\section{Implications for nursing}

As shown here and elsewhere (Winterbottom \& Harcourt, 2004), patients with melanoma utilize a wide range of coping strategies, both adaptive and maladaptive. These strategies could be optimized with healthcare professional support to direct them towards appropriate resources, as they are often underutilized (Eakin \& Strycker, 200I). In a recent study also surveying MNC members, 68\% reported that they were not provided with educational resources to assist them in understanding the diagnosis, and 60\% felt they did not receive sufficient information about treatment options (Hetz \& Tomasone, 20I2). Katz et al. (2013) showed that $44 \%$ of cancer patients who were not provided with links to medically relevant websites wished their doctors had supplied them with such links. Designated nursing support for melanoma patients has proven useful for provision of education, emotional support and information consolidation (Winterbottom \& Harcourt, 2004; Wheeler, 2006; Dancey et al., 2005). Nurses have multiple roles in the care of patients with melanoma; they are communicators, patient advocates, educators and coaches. They can evaluate a patient's understanding of the disease, its treatment, expectations and symptom management longitudinally from the time of diagnosis (Rubin et al., 2013). Given the fast pace of most oncology clinics, it is especially important for nurses and other members of the psychosocial team to be involved in sharing these resources with patients (Table 2). Specific suggestions for increasing patient uptake of support resources include early provision of an "emotional and informational support package". This could include pamphlets from patient advocacy groups, links to online support groups and information about upcoming public patient education sessions. As patient needs evolve over time, support and resource provision needs to continue throughout the care process.

\section{Limitations}

This study provides valuable information about the relationships between social support levels and coping strategies of Canadian melanoma patients; however, several limitations exist. Data were only collected from MNC members with a

\section{REFERENCES}

Boyle, D.A. (2003). Psychological adjustment to the melanoma experience. Semin Oncol Nurs, 19, 70-77.

Costa Requena, G., Salamero, M., \& Gil, F. (2007). Validity of the questionnaire MOS-SSS of social support in neoplastic patients. Medicina Clinica (Barc),128, 687-691. melanoma diagnosis, which limited the sample size. Only I4\% of patients were under the age of 50 , which is important because younger patients may cope differently with the diagnosis. Loquai et al. (2014) showed that younger age was associated with significantly more distress related to emotional variables, social and family problems, whereas older melanoma patients were distressed by functional limitations in daily living. Response rates were lower than expected, perhaps due to the method by which the survey was distributed. Internet questionnaires have been shown to produce lower response rates than mailed paper surveys amongst breast cancer patients (Kongsved, Basnov, Holm-Christensen, \& Hjollund, 2007). Strategies for increasing response rates from online surveys should be a topic of further investigation. Future research could usefully survey outpatients visiting melanoma clinics. Cancer stage was not controlled; disease severity could impact both social support and coping strategy utilization. The survey was only available online via email, limiting the sample to those with computer and Internet proficiency, and potentially excluding patients with the lowest social support. This study examined social support and coping strategies at one time point; these determinants of health can change over time and with increasing or regressing disease severity (Thompson, Rodebaugh, Perez, Schootman, \& Jeffe, 20I3). The majority $(96 \%)$ of patients were Caucasian. Ongoing research with a larger sample of other ethnicities and cultures is warranted.

\section{CONCLUSION}

We conclude that perceived social support amongst melanoma patients could be improved by increased provision and uptake of resources providing emotional and informational support. Patients would gain tools to apply the coping strategies that they report most frequently utilizing, namely active coping and the use of emotional support. It appears that health care provider assessment of available social support at initial diagnosis is important to identify those patients most likely to benefit from additional resources. Health care professionals can usefully evaluate social support and have the opportunity to provide targeted education about the emotional and informational support resources available to melanoma patients throughout the cancer journey.

\section{ACKNOWLEDGEMENT}

We would like to thank MNC staff members Diane Harty and Tanya Hesser for their suggestions in the development of this manuscript. We also thank the MNC members who dedicated their time to respond to the survey and recognize the work of the nurses involved in their health care.

Daly, B.J., Douglas, S., Lipson, A., \& Foley, H. (2009). Needs of older caregivers of patients with advanced cancer. J Am Geriatr Soc, Suppl, 2, 293-295.

Dancey, A., Rayatt, S., Courthold, J., \& Roberts, J. (2005). Views of UK melanoma patients on routine follow-up care. Brit J Plast Surg, 58, 245-250. 
Devine, D., Parker, P.A., Fouladi, R.T., \& Cohen. L. (2003) The association between social support, intrusive thoughts, avoidance, and adjustment following an experimental cancer treatment. Psycho-Oncol, 12, 453-462.

Eakin, E.G., \& Strycker, L.A. (200I). Awareness and barriers to use of cancer support and information resources by HMO patients with breast, prostate, or colon cancer: Patient and provider perspectives. Psycho-Oncol, 10, IO3-II3.

Fawzy, N.W. (1995). A psychoeducational nursing intervention to enhance coping and affective state in newly diagnosed malignant melanoma patients. Cancer Nurs, 18, 427-438.

Garbe, C., \& Leiter, U. (2009). Melanoma epidemiology and trends. Clin Dermatol, 27, 3-9.

Gil, F., Costa, G., Hilker, I., \& Benito, L. (20I2). First anxiety, afterwards depression: Psychological distress in cancer patients at diagnosis and after medical treatment. Stress Health, 28, 362-367.

Hamama-Raz, Y., Solomon, Z., Schachter, J., \& Azizi, E. (2007) Objective and subjective stressors and the psychological adjustment of melanoma survivors. Psycho-Oncol, 16, 287-294.

Hetz, S., \& Tomasone, J.R. (20I2). Supportive care needs of Canadian melanoma patients and survivors. Can Oncol Nurs J, 22, 248-25I.

Kasparian, N.A., McLoone, J.K., \& Butow, P.N. (2009). Psychological responses and coping strategies among patients with malignant melanoma. Arch Dermatol, 145, I4I5-I427.

Katz, J.E., Roberge, D., \& Coulombe, G. (2013). The cancer patient's use and appreciation of the internet and other modern means of communication. Technol Cancer Res Treat, 13, 477-484.

Kongsved, S.M., Basnov, M., Holm-Christensen, K., \& Hjollund, N.J. (2007). Response rate and completeness of questionnaires: A randomized study of internet versus paper-and-pencil versions. $J$ Med Internet Res, 9, e25.

Lehto-Jarnstedt, U.S., Ojanen, M., \& Kellokumpu-Lehtinen, P. (2004) Cancer-specific social support received by newly diagnosed cancer patients: Validating the new structural-functional social support scale (SFSS) measurement tool. Support Care Canc, 12, 326-337.

Lichtenthal, W.G., Cruess, D.G., Schuchter, L.M., \& Ming, M.E. (2003), Psychosocial factors related to the correspondence of recipient and provider perceptions of social support among patients diagnosed with or at risk for malignant melanoma. $J$ Health Psychol, 8, 705-719.

Loquai, C., Scheurich V., Syring N., Schmidtmann I., Muller-Brenne T., Werner A., ... Beutel, M.E. (20I4). Characterizing psychosocial distress in melanoma patients using the expert rating instrument PO-Bado SF. JEADV. doi:Io.IIII/jdv.I236I [Epub ahead of print]

Melanoma Network of Canada. Retrieved from www. melanomanetwork.ca

Murtaza Kasi, P., Naqvi, H.A., Afghan, A.K., Khawar, T., Khan, F.H., Khan, U.Z., ... Khan, H.M. (2OI2). Coping styles in patients with anxiety and depression. ISRN Psych, ID, 128672, I-7.

Paredes, T.F., Canavarro, M.C., \& Simões, M.R. (20I2). Social support and adjustment in patients with sarcoma: The moderator effect of the disease phase. J Psychosoc Oncol, 30, 402-425.

Rand Health. (20II). Medical outcomes study: Social support survey scoring instructions. Retrieved from http://www.rand.org/health/ surveys_tools/mos/mos_socialsupport_scoring.html
Rubin, K.M. (2013) Management of primary cutaneous and metastatic melanoma. Sem Oncol Nurs, 29, 195-205.

Rudy, R.R., Rosenfeld, L.B., Galassi, J.P., Parker, J., \& Schanberg, R. (200I). Participants' perceptions of a peer-helper, telephonebased social support intervention for melanoma patients. Health Commun, 13, 285-305.

Schreurs, K.M. \& DeRidder, D.T. (I997). Integration of coping and social support perspectives: Implications for the study of adaptation to chronic diseases. Clinic Psychol Rev, 17, 89-II2.

Sherbourne, C.D., \& Stewart, A.L. (I99I). The MOS social support survey. Soc Sci Med, 32, 705-7I4.

Sollner, W., Zschocke, M., Zingg-Schir, B., Stein, G., Rumpold, P., Fritsch, P. \& Augustin, M. (I999). Interactive patterns of social support and individual coping strategies in melanoma patients and their correlations with adjustment to illness. Psychosomatics, 40, 239-250.

Thompson, T., Rodebaugh, T.L., Perez, M., Schootman, M., \& Jeffe, D.B. (20I3). Perceived social support change in patients with early stage breast cancer and controls. Health Psychol, 32, 886-895.

Trapp, M., Trapp, E.M., Richtig, E., Egger, J.W., Zampetti, A., Sampogna, F., ... Linder, M.D. (20I2). Coping strategies in melanoma patients. Acta Derm-Venereol, 92, 598-602.

Trask, P.C., Paterson, A.G., Hayasaka, S., Dunn, R.L., Riba, M., Johnson, T. (200I). Psychosocial characteristics of individuals with non-stage IV melanoma. J Clin Oncol., 19(II), 2844-2850.

Vurnek, M., Buljan, M., \& Situm, M. (2007). Psychological status and coping with illness in patients with malignant melanoma. Coll Antropol, 31, 53-56.

Wheeler, T. (2006). Psychological consequences of malignant melanoma: Patients' experiences and preferences. Nurs Stand, 21, $42-46$.

Winterbottom, A., \& Harcourt, D. (2004). Patients' experience of the diagnosis and treatment of skin cancer. J Adv Nurs, 48, 226-233.

Yusoff, N., Low, W.Y., \& Yip, C.H. (2010). Reliability and validity of the brief COPE scale (English version) among women with breast cancer undergoing treatment of adjuvant chemotherapy: A Malaysian study. Med J Malaysia, 65, 4I-44.

Zabora, J., Brintzenhofeszoc, K., Curbow, B., Hooker, C., \& Piantadosi, S. (200I). The prevalence of psychological distress by cancer site. Psycho-Oncol, 10, 19-28.

Zhou, E.S., Penedo, F.J., Bustillo, N.E., Benedict, C., Rasheed, M., Lechner, S., ... Antoni, M.H. (2010). Longitudinal effects of social support and adaptive coping on the emotional well-being of survivors of localized prostate cancer. J Support Oncol, 8, I96-20I.

\section{SUPPLIERS}

Fluid Surveys. www.fluidsurveys.com, Chide.it Inc., I729 Bank StreetSuite 200, Ottawa, ON KIV $7 Z_{5}$

GraphPad Prism Software. www.graphpad.com, GraphPad Software, Inc. Version 6.oc. La Jolla, California, USA. 